This item was submitted to Loughborough's Research Repository by the author.

Items in Figshare are protected by copyright, with all rights reserved, unless otherwise indicated.

\title{
Steel column response to thermal and long duration blast loads inside an air blast tunnel
}

PLEASE CITE THE PUBLISHED VERSION

https://doi.org/10.1080/15732479.2019.1635627

\section{PUBLISHER}

(C) Taylor \& Francis (Routledge)

\section{VERSION}

AM (Accepted Manuscript)

\section{PUBLISHER STATEMENT}

This is an Accepted Manuscript of an article published by Taylor \& Francis in Structure and Infrastructure Engineering on 11 July 2019, available online: http://www.tandfonline.com/10.1080/15732479.2019.1635627.

\section{LICENCE}

CC BY-NC-ND 4.0

\section{REPOSITORY RECORD}

Clough, Laurence G., and Simon Clubley. 2019. "Steel Column Response to Thermal and Long Duration Blast Loads Inside an Air Blast Tunnel”. figshare. https://hdl.handle.net/2134/37406. 


\section{Steel Column Response to Thermal and Long Duration Blast Loads inside an Air Blast Tunnel}

*Laurence G Clougha MEng(Hons) PhD CEng MICE FHEA

Simon K Clubley ${ }^{\mathrm{b}}$ BEng(Hons) MBA PhD EurIng CEng MICE MInstP MBCS CITP

${ }^{a}$ School of Civil Engineering and Surveying, University of Portsmouth, Portsmouth, UK; ${ }^{b}$ School of Architecture, Building and Civil Engineering, Loughborough University, $U K$

*Corresponding Author Email: laurie.clough@port.ac.uk Tel. +44 (0) 2392842409 


\section{Abstract}

All explosions emit both thermal and blast energy. In recent years there have been several accidental explosive events that have emitted high thermal loads with the potential to cause thermo-mechanical damage to structures. Attempts to experimentally simulate these thermal loads and observe the response of structures to combined thermal and blast loads have not proven successful. This paper focuses on the design of, and results from a series of experimental trials investigating the response of steel columns to combined thermal loads from ceramic heating elements and long-duration blast loads within an Air Blast Tunnel (ABT). The combined effect of compressive loads from heavy-duty springs is also shown. The trials concluded that the ceramic heating elements were suitable to heat steel columns to levels initiating thermo-mechanical damage. Results from the tests showed an increased structural response in the columns subject to high thermal, compressive and blast loads compared to the isolated blast load. Numerical modelling of the columns is detailed and compared to trial results, providing validation for the computational methods. The experimental trials set a benchmark for future trials and provided results to validate the synergistic response of steel structures to combined blast and thermal loads from explosive events.

Keywords: Long-Duration Blast, Axial Compression, Steel Column, Thermomechanical 


\section{Introduction}

In recent years there have been a series of high yield explosive disasters with significant thermal loads emitted. By example the Buncefield oil refinery disaster $(2005,250$ tonnes TNT eq., $1000^{\circ} \mathrm{c}$ approx., 500msec duration) Burgan, 2009 (Burgan, 2009), Atkinson, 2011 (Atkinson, 2011), the West Texas fertiliser factory explosion (2013, 10 tonnes TNT eq. (Loftis, 2013)), the Tianjin warehouse disaster (2015, 21 tonnes TNT eq. ("China explosions: What we know about what happened in Tianjin," 2015)) and near earth object detonations (Chelyabinsk Meteor, Russia, 2013, 400-500 kilotons TNT eq. ("Russian meteorite blast explained: Fireball explosion, not meteor shower ", 2013)).

There have been numerous attempts to experimentally simulate the high thermal loads emitted from explosive events akin to Buncefied, West Texas, Tianjin and Chelyabinsk. Initial experiments undertaken by Griff, 1972, used rocket propellant (Griff, 1972), followed by the use of Aluminium oxide and rotating tables by Teel, 1981 (Teel, 1981). The use of a multi nozzle Thermal Radiation Simulator (TRS) inside an ABT was investigated by Borgatz, 1985 (Borgartz, 1985) and Gratias, 1987 (Gratias, 1987). The design of a "Hi-Thermal Simulator" is discussed by Zavitsanos, 1998 (Zavitsanos, 1998). During these previous attempts to experimentally simulate high thermal explosive loading several problems occurred; including the detrimental presence of combustion products, the ability to produce accurate thermal profiles, safe use of high combustible materials and production of sufficiently large thermal loads for full structural targets. There has been no research into the response of full structural elements subject to combined thermal and long duration blast loading. Due to the difficulties of combined thermal and blast experimental trials a new method of heating structural elements via ceramic heating elements (Ceramicx, 2015) was investigated. 
This paper details the design and results from a series of experimental trials to examine the response of full structural steel columns to thermal, compression and long duration blast load. Three sets of experimental trials are discussed in this paper; two preliminary trials and one main series. The initial preliminary trial investigated the suitability of ceramic heating elements (Ceramicx, 2015) to heat the surface of structural steel columns to temperatures akin to fire loading (BSi, 2002a). The second preliminary trial investigated the response of structural column sections subject to long duration blast loads within the Air Blast Tunnel (ABT) at MOD Shoeburyness. The third and main series of trials investigated the thermo-mechanical response of steel columns subject to combined compression (representing in-service loads), thermal and long duration blast loads within the ABT. Thus determining if steel columns subject to a combination of these loads exhibit a different response than columns subject to blast loads alone.

The experimental trials undertaken have demonstrated a successful use of a new combined blast load and heating methods, setting the benchmark for further testing in this area. Results from the trials are used to corroborate the potential synergistic response observed in steel structures subject to combined thermal and blast explosive loads.

\section{Experimentation}

Three sets of experimental trials are detailed in this paper; two preliminary trials and one series of combined load trials conducted in the ABT. The purpose of the preliminary trials was to assess the suitability of the test pieces (column sections), determine an appropriate range of parameters, evaluate the suitability of equipment (ceramic heating elements and heavy duty springs) and highlight any required 
modifications to the test rig before the main trial series. The detailed design, set up, observations and results for each trial are described in this section.

\subsection{Preliminary Trial 1: Ceramic Heating Elements}

The first preliminary trial investigated the use of ceramic heating elements (Fig.1) (Ceramicx, 2015) to heat the surface of structural steel columns to temperatures akin to those reached in internal fires $\left(850^{\circ} \mathrm{C}\right.$ in $\left.30 \mathrm{mins}\right)(\mathrm{BSi}, 2002 \mathrm{a})$. The relatively slow increase of heat representative of fire loads was selected for experimentation opposed to the intense heat akin to the radiative and convective thermal energy emitted from explosive events. This was due to the control of temperature levels and directional/locational assignment of heat on the columns afforded by the ceramic heating elements. The use of ceramic heating elements was also driven by cost, safety and testing practicalities. To date, experiments investigating intense thermal simulation have either produced high, but inaccurate thermal profiles on large structural elements or accurate, controlled thermal profiles on small (non-structural) samples. No testing has managed to combine controlled, accurate thermal profiles on full structures in combination with long duration blast loads inside the ABT (Simon, 2008). The preliminary trial was designed to assess the effectiveness of the ceramic heating elements to heat the columns and the suitability of the heavy duty springs to apply compressive loads into the columns.

[Fig. 1 near here]

Structural columns were heated using eight (per column) Ceramicx (Ceramicx, 2015) heating elements $(245 \mathrm{~mm} \times 60 \mathrm{~mm} \times 100$ Watt Full Trough Element (FTE)) (Fig.1). The elements were positioned in a circular array inside a thermally insulated aluminium box (Fig.2). The box was 500mm (h) x 300mm (w) x $300 \mathrm{~mm}$ (d) 
constructed from thin gauge aluminium sheet with an insulating fabric on the inside face. The ceramic elements were positioned 100mm from the column surface. During heating the thermally insulated box was held in position over the central $500 \mathrm{~mm}$ length of each column (location of maximum flexural stress under blast) using a blast sequenced "drop down" frame (Fig.3). The frame was a prototype for the main series of ABT trials, designed to hold the thermally insulated box around the columns during the initial heating phase then "drop down" prior to the blast arrival to avoid any unwanted interaction between the box and blast flow field. The drop down frame also minimised the duration between the end of column heating phase to the arrival of blast wave maintaining column surface temperatures at a high level without significant cooling and potential reversal of thermo-mechanical actions (contraction, snap-back post-buckling) (Shepherd, 2011).

[Fig. $2 \& 3$ near here]

The steel columns were held in a rig using a sleeved connection at the top and a sleeved connection with a heavy duty spring at the base (IST "Closed and Ground" (IST, 2015), in BS5216 patented carbon (Bsi, 1991)). Column sections tested during the thermal pre-cursor trials were (i) 50x25x2mm Rectangular Hollow Section (RHS), (ii) 25x25x2mm Square Hollow Section (SHS) and, (iii) 33.7x3mm Circular Hollow Section (CHS) in S355 J2C cold formed steel (BSEN 10219-1) (Bsi, 2006a). Each column was $3 \mathrm{~m}$ in length. The tolerance for straightness of the SHS and RHS is $0.15 \%$ of the full length plus $3 \mathrm{~mm}(7.5 \mathrm{~mm}$ total), the straightness tolerance for the CHS is $0.2 \%$ of the full length plus $3 \mathrm{~mm}$ (9mm total), in accordance with (BSEN 10219-2) (BSi, 2006b).

The column's thin gauge walls allowed rapid thermal conduction and the low compressive/buckling capacities enabled the effective use of heavy duty springs, which 
only impart low compressive loads. Temperatures were recorded using six (K-type) thermocouples placed along the central length of each column from $1100 \mathrm{~mm}$ to $2100 \mathrm{~mm}$, at $200 \mathrm{~mm}$ centres. The thermocouples were attached to the surface of the steel columns using thin gauge steel wire tied around the external surface of the columns. (Fig.3). Zemic BM23-C3-1T-3B (BSi, 2006c) load cells were used to record the compressive loads applied from the springs.

Table 1 shows results of maximum temperatures and compressive load increases recorded at each column during the preliminary thermal trial. The peak temperature reached was $572^{\circ} \mathrm{C}$ in the RHS. The SHS and CHS exhibited visible lateral bending deformation of $15 \mathrm{~mm}$ (SHS) and 10mm (CHS) during heating. Lateral displacement of the slender columns was caused by longitudinal expansion of the columns against the top and base supports. Compressive load increases (table 1) recorded by the load cells also indicate the longitudinal expansion of the column sections.

[Table 1 near here]

Fig. 4 shows the temperatures recorded by thermocouples on the RHS. A peak temperature of $573^{\circ} \mathrm{C}$ was recorded at $1700 \mathrm{~mm}$ (200mm above centre), 22 minutes after the start of heating. The ceramic heating elements were selected for the main series of ABT trials. This was due to the high temperatures the elements could maintain to allow thermo-mechanical changes in the columns.

[Fig. 4 near here]

\subsection{Preliminary Trial 2: ABT / Column Selection}

The second preliminary trial was undertaken to determine the extent of elastic or plastic deformation exhibited by the selected column sections (50x25x2RHS, $25 \times 25 \times 2$ SHS and 33.7x3CHS) when subject to long duration blast load within the ABT. Sections were 
selected with low sectional stiffness and a sufficiently wide face to absorb energy from the blast wave. Very narrow sections were not selected as they would be subject to a relatively low net force due to rapid equalisation of load caused by blast wave clearing around the column section.

Column sections were positioned in the $10.2 \mathrm{~m}$ diameter section of the ABT (Fig.5). Blast loads with 55kPa peak pressures and 150msec positive phase durations can be achieved in this section. The Rarefaction Wave Eliminator (RWE) at the open end of the tunnel limits the return of negative pressures (Fig.5). $3 \mathrm{~m}$ long columns were fixed as cantilevers (for ease of construction) to the base of the tunnel using a sleeve and large steel plate (Fig.6). Columns were in S355 J2C cold formed steel (BSEN 10219-1) (Bsi, 2006a). Incident (Endevco - 8510) and dynamic (Kulite - 20D) pressure gauges were positioned adjacent to the columns in the ABT (Fig.6). Deformation of the columns during the trial was recorded using high speed Phantom cameras (2000 frames per second (fps)).

[Fig. 5 near here]

A peak incident pressure of $64.68 \mathrm{kPa}$ with a positive phase duration of $173 \mathrm{msec}$ was recorded during the trial (Fig.6). Fig 6 shows the recorded pressure-time history smoothed with a 1000 point average decimation. A permanent deformation of $125 \mathrm{~mm}$ was recorded at the top of the SHS after the trial, the CHS and RHS showed no visible permanent deformation. The RHS was positioned with its strong axis parallel to the blast wave, if the weaker axis had been positioned parallel to the blast wave a larger deformation would have been observed (as demonstrated in the core trial series). Fig. 6 shows images from the high speed cameras at 113, 309 and $492 \mathrm{msec}$ after blast arrival. The SHS exhibited the largest positive deflection before oscillating and settling at $125 \mathrm{~mm}$. The RHS and CHS showed smaller elastic deformations before oscillating and 
returning to zero. Deflections at the top of the column were not recorded during the trial as the high speed cameras were focused on the base of the columns. The magnitude and nature (elastic/plastic) of the deformation exhibited by the three column sections during the ABT pre-cursor trial provided confidence towards using the sections for the subsequent main trial series.

[Fig. 6 near here]

\subsection{Main Trials: Combined ABT Trials}

\subsubsection{Trial Design}

The combined ABT trials tested 54 columns for a range of thermal and compression loads combined with long duration blast loads inside the ABT. Six ABT trials were undertaken with nine columns per trial. The target blast pressure of $55 \mathrm{kPa}$ was determined by results from previous ABT trials (L. G. Clough, Clubley, S.K., 2013; S. K. Clubley, 2014; Gregory, 1982; Pearson, 1981). The applied compressive loads were governed by column buckling capacities. The thermal load and column sizes were decided during the preliminary trials.

The $3 \mathrm{~m}$ length column sections selected were 50x25x2RHS, $25 \times 25 \times 2$ SHS and 33.7x3CHS3m in S355 J2C cold formed steel (BSEN 10219-1) (Bsi, 2006a). Compressive and thermal loads applied to each column varied throughout the series in combination with a consistent peak blast pressure of $55 \mathrm{kPa}$ and duration of $150 \mathrm{msec}$ (ABT at 100\% capacity). Fig.7 shows a plan view of the trial set up; three rigs were positioned in the $10.2 \mathrm{~m}$ diameter section of the $\mathrm{ABT}$ with each rig holding a RHS, CHS and SHS. The rig furthest from the RWE (Rig 1) held the columns with pinned connections at both ends and no additional thermal or compression loads. During the final three trials aerodynamic wing plates were fitted to the pinned columns. These wing 
plates were designed to increase the projected load from the blast wave, representing additional lateral load transferred from building cladding. The wings were $250 \mathrm{~mm}$ wide, 3mm thick hot rolled sheet steel (BS EN 10025, 2004 S275 JR (BSi, 2002b)), fitted to the columns with U-bolts.

[Fig. 7 near here]

The central rig and rig nearest to the RWE (Rigs $2 \& 3$ ) applied thermal and compression loading to the columns prior to the blast wave arrival. The rig design was based on the prototype rig used during the preliminary thermal trial. Fig. 8 shows an elevation drawing of the rig and photos of the thermal boxes (trial 1 and trials 2-6). The rig used sleeved connections at the top and a sleeved spring connections at the base. [Fig. 8 near here]

Compressive loads were applied to the columns using heavy duty springs (IST “Closed and Ground" (IST, 2015)) in BS5216 patented carbon (Bsi, 1991). Each spring was specified to impart a compressive load of approximately $50 \%, 75 \%$ or $90 \%$ of the column section buckling capacity (BSi, 2006b), applying a range of in-service to near failure compressive stresses. The columns buckling capacities were $3.1 \mathrm{kN}$ (SHS), $5.72 \mathrm{kN}$ (RHS) and 6.96kN (CHS). The applied compressive loads were recorded by Zemic BM23-C3-1T-3B load cells (BSi, 2006c). Actual compressive loads recorded at the start of each trial are shown in Table 2, due to a trial error the SHS was stressed beyond its buckling capacity during the fifth and sixth trials. Figure 9 shows the base of the columns with sleeved spring connections. The process of fixing the spring and transferring the compression from the springs to the columns was undertaken as follows:

- Locate spring inside sleeve.

- Increase torque on spring by tightening nuts on $22 \mathrm{~mm}$ diameter welded bolts. 
- Position column in sleeved connection at top and base.

- Loosen the nuts to allow the torqued spring to impart vertical compressive load to column.

- Record compression using calibrated load cells.

[Fig. 9 near here]

The thermally insulated boxes with ceramic heating element were used on rigs 2 and 3 to heat the column during the initial phase of each trial. Three boxes were fixed to a drop-down frame on each rig. The frames were held vertically in position with elastic cord and high strength wires. In the vertical location the boxes were positioned over the central $500 \mathrm{~mm}$ of the columns. At the end of the heating phase of each trial the wires were remotely cut from a safe bunker, allowing the thermal boxes to fall back on to cushioned air-bags. Three thermocouples (K-type) were fixed on to the surface of each heated column using thin gauge wire at $1250 \mathrm{~mm}, 1500 \mathrm{~mm}$ and $1750 \mathrm{~mm}$. Table 2 shows the peak recorded temperatures.

[Table 2 near here]

Three sets of pressure gauges were positioned adjacent to each rig, each set consisted of an incident (Endevco - 8510) and dynamic (Kulite - 20D) pressure gauge. A reflected (Endevco) pressure gauge was mounted onto each heavy structural rig (150mm wide channel section).

\subsubsection{Trial Results \& Discussion}

Six combined load ABT trials were performed recording data regarding the response of steel columns to compressive, thermal and long duration blast loads. Pressures, temperatures, compressive loads, and deflections were recorded for 54 columns over the trial series. Initial observations showed that the RHS exhibited the largest permanent 
deformations, followed by the SHS and CHS. Columns subject to thermal load also exhibited higher permanent deflections.

Fig. 10 shows the incident pressure recorded during the first trial at rig 1 (raw data), the peak incident pressure is $60.3 \mathrm{kPa}$, with a $182 \mathrm{msec}$ duration. To reduce experimental noise the data is decimated (8000 points average). Post decimations the peak incident pressure is $46.1 \mathrm{kPa}$. A high decimation was necessary to enable the efficient use of the data in subsequent computational analyses. Table 3 shows the recorded peak incident pressures at each rig during the six trials and Fig. 11 shows the recorded incident pressure histories. Figs. 12 and 13 show the recorded dynamic and reflected pressures at the three rigs during the six trials (decimated 8000 points average). For trial 1, rig 1, the peak dynamic and reflected pressures were $7.4 \mathrm{kPa}$ and $55.5 \mathrm{kPa}$. The positive phase duration of the dynamic and reflected pressures recorded at trial 1, rig 1 were $360 \mathrm{msec}$ and $192 \mathrm{msec}$.

[Fig. 10, 11, 12, $13 \&$ Table 3 near here]

Peak temperatures recorded at rigs two and three during each trial are shown in Table 2. On each column the peak temperature was typically recorded at the central location, ranging from $344.5^{\circ} \mathrm{C}$ to $572^{\circ} \mathrm{C}$ over the six trials. The peak temperatures varied by a maximum of $46^{\circ} \mathrm{C}$ across the three sections (RHS, CHS, SHS) on the same rig, during the same trial. The lowest set of temperatures $\left(201-354^{\circ} \mathrm{C}\right)$, shown in Fig.14, recorded during the blast application during trial one on rig two (before the introduction of the front aluminium plate on the thermal box). The highest set of recorded temperatures $\left(297-572^{\circ} \mathrm{C}\right)$, shown in Fig. 15 were recorded prior to blast arrival during trial four on rig three.

[Fig. $14 \& 15$ near here] 
Temperatures recorded during the first trial peaked at $385.3^{\circ} \mathrm{C}$, much lower than the peak temperature recorded during the preliminary thermal trial $\left(572^{\circ} \mathrm{C}\right)$. This was due to lower environmental temperatures and presence of wind within the ABT compared to the internal lab conditions of the preliminary trial. Higher peak temperatures were achieved in subsequent trials by the addition of insulated aluminium sheets to the open front faces (blast facing) of the thermal boxes (2 - 6) (Fig.8). A slot in the aluminium sheet enabled the boxes to fit around the columns during heating phase.

Table 2 shows recorded compressive loads at the start of each trial. The maximum-recorded initial compressive load was $5.73 \mathrm{kN}$ on a CHS, on rig 3 , during trial 4. Load cells recorded increases in the applied compressive load during the heating phase of each trial. Fig. 16 shows the recorded compressive load on the RHS, CHS and SHS on rig 2 (applied heat) and rig 3 (no heat) during trial 2. Compressive loads increased by $0.19 \mathrm{kN}$ (RHS), $0.22 \mathrm{kN}$ (CHS) and $0.15 \mathrm{kN}$ (SHS) on rig 2 during the heating phase. Fluctuations were also recorded during and after the blast phase (phase not shown in Fig.16), of each trial, indicating a dynamic response.

[Fig. 16 near here]

Following each trial, permanent "post-shot" deflections were recorded along the length of each column. Lateral deflections were recorded after the columns were removed from the rigs at nine points along the length of each column from $1100 \mathrm{~mm}$ to 1900mm. Deflections were recorded against a straight tape using a pair of Vernier Calipers. The total measurement error was $2 \mathrm{~mm}$; due to a $0.5 \mathrm{~mm}$ human error and $1.5 \mathrm{~mm}$ error in tape straightness. Figure 17 and 18 show the post shot permanent deflected shape of the columns (trials 1 and 4). A Fourier transform smoothing at a smoothing window of 10 to 100 has been applied to the raw data. Table 4 shows the maximum post-shot deflections (after removal from rig) of each column for all trials. 
The RHS columns exhibited the largest deflections throughout the trials (trial one: Rig 1: $33 \mathrm{~mm}$, Rig 2: $32 \mathrm{~mm}$ and Rig 3:29mm). During trials four, five and six the RHS, CHS and SHS in the pinned rig were fitted with wing sections. This significantly increased the deflections (maximum 118.7mm, RHS, trial 5), as the wings transferred more blast load to the columns. The columns in trial one (rigs two and three) were subject to low temperatures, whereas the columns in the trial four (rigs two and three) were subject to high temperatures (see Table 2). The maximum permanent deflection (after removal from rig) was much larger for the RHS in trial four, rig two (high temperature: $63.2 \mathrm{~mm}$ ), compared with trial one, rig two (low temperature: $32.4 \mathrm{~mm}$ ). [Fig. $17 \& 18$ and Table 4 near here]

Figs.19 and 20 show the maximum deflected shapes and midpoint deflection histories of the columns on rig two during trial one (T1.R2) and on rig two during trial four (T4.R2). The deflection versus time histories were formed by analysing the high speed Phantom videos positioned adjacent to each rig. Error from vibration of the high speed cameras during each trial was mitigated by subtracting the apparent movement of the LED (mounted on the heavy structural rig) from the apparent movement of the column midpoints. RHS columns exhibited the highest elastic deflections (T1.R2 = $159 \mathrm{~mm}, \mathrm{~T} 4 . \mathrm{R} 2=164 \mathrm{~mm}$ ), followed by a harmonic response and in-situ permanent deflections $(\mathrm{T} 1 . \mathrm{R} 2=63 \mathrm{~mm}, \mathrm{~T} 4 . \mathrm{R} 2=72 \mathrm{~mm})$. SHS columns also exhibited large elastic deflection $(\mathrm{T} 1 . \mathrm{R} 2=98 \mathrm{~mm}, \mathrm{~T} 4 . \mathrm{R} 2=101 \mathrm{~mm})$ followed by a harmonic response and lower in-situ permanent deflections $(\mathrm{T} 1 . \mathrm{R} 2=15 \mathrm{~mm}, \mathrm{~T} 4 . \mathrm{R} 2=8 \mathrm{~mm})$. The CHS columns exhibited small elastic deflections $(\mathrm{T} 1 . \mathrm{R} 2=48 \mathrm{~mm}, \mathrm{~T} 4 . \mathrm{R} 2=66 \mathrm{~mm})$ followed by a harmonic response and very small or negligible in-situ permanent deflections (T1.R2 = $8 \mathrm{~mm}, \mathrm{~T} 4 . \mathrm{R} 2=4 \mathrm{~mm})$.

[Fig. $19 \& 20$ near here] 
Fig.21 shows the final deflections of the RHS columns plotted against the maximum temperature recorded on each column. An upward trend in the relation of final deflection to the maximum temperature from $350^{\circ} \mathrm{C}$ to $550^{\circ} \mathrm{C}$ is shown. This sensitivity response envelope correlates with a reduced Young's Modulus of steel at temperatures above $200^{\circ} \mathrm{C}$ and reduced yield strength with temperatures above $400^{\circ} \mathrm{C}$ (BSi, 2005b). Recorded deflections at ambient (no applied temperature) conditions are also shown.

[Fig. 21 near here]

Fig.22 displays the final deflections of the SHS columns plotted against the applied compressive load at the start of each trial. An upward trend is observed in the final deflections with an increase in applied compressive load. During the second trial the drop-down frame on rig 2 did not drop back on the cushioned air bags as planned after remote cutting of the holding wire prior to the blast. Modifications to the thermal boxes (widening of column gap), and use of elastic cord to pull the boxes on to the air bags were introduced for subsequent trials (3 - 6). During the fourth trial the bolts fixing the pinned CHS column with wings to the rig failed in shear. A larger $(20 \mathrm{~mm})$ diameter bolt was subsequently specified for the remaining trials on all columns with additional wing sections.

[Fig. 22 near here]

\section{ABT Trials: Computational Analysis}

\subsection{Computational Method}

Predictive computational models were developed for the columns subject to the compressive, thermal and long duration blast loads from the ABT trials. Thermal and structural coupled models were established using the non-linear FEA code, LUSAS. A 
continuum quadratic solid elements (HX20), LUSAS, 2011 (LUSAS, 2011) was chosen for geometric and material compatibility. Due to large rotations and displacements (geometric non-linearity) exhibited by the columns a Total Lagrangian formulation was adopted. An implicit analysis was selected over an explicit analysis due to incompatibility of an explicit analysis with coupled manual time steps, Rayleigh damping parameters and stress variations across element thicknesses. Initial static models representing the columns under self-weight and compressive loads were developed, following which an eigenvalue analysis was performed for each column section (RHS, CHS and SHS). Natural frequencies were determined in order to calculate the Rayleigh damping parameter with a damping ratio of 3\%, Davison, 2012 (Davison, 2012). The Rayleigh damping parameters for the three columns sections with sleeved end connections (rigs 2 and 3) and pinned end connections (rig 1) are shown in table 5. This modelling procedure was adopted throughout the whole study, including numerical simulations of steel plates inside explosive fireballs (L. G. Clough, Clubley, S.K., 2014) and a study into the synergistic response of steel columns to combined intense thermal and blast loads from explosive events (L. G. Clough, 2017). The following sections detail how the recorded pressures, temperatures and compressive loads from the ABT trials were converted to applied loads within the computational models.

[Table 5 near here]

The recorded reflected pressures (Fig.13) were applied to the front (blast facing) faces of the SHS, RHS and CHS columns in combination with the recorded dynamic pressures (with appropriate drag coefficients). Reflected pressures were applied to each column front face after raw data decimation with 100 point average to remove erroneous high peaks and troughs (noise). Fig.23 shows the raw and 100 point 
decimated reflected pressure data recorded during Trial 1 at Rig 1 (between 341.2 and 342.6msec). The recorded dynamic pressures were applied to the rear face of the structural column sections with drag coefficients of 0.4 (RHS \& SHS) and 0.3 (CHS), (S.K. Clubley, 2013), (Bsi, 2005a). The applied pressures were linearly smoothed around the faces of the columns to remove any unrealistic steps in the applied pressure. [Fig. 23 near here]

The temperatures recorded at $1250 \mathrm{~mm}, 1500 \mathrm{~mm}$ and $1750 \mathrm{~mm}$ on each thermally loaded column were directly input as steel surface temperatures in the FEA models. Initial assumptions were made regarding the temperatures at the top and base of each column; the base was assumed to stay at room temperature throughout the heating phase and the top was assumed to increase to half the temperature recorded at top thermocouple $(1750 \mathrm{~mm})$. Smoothing variations were applied to temperatures along the length of each column. Fig.24 shows the applied temperature variation along the length of the RHS column in trial 3, rig 3.

[Fig. 24 near here]

Compressive loads imparted by the heavy duty springs on to the base of each column, recorded by the load cells (Zemic BM24R-C3-1T-3B (BSi, 2006c)), were applied as spring supports in the column models with an equivalent stiffness of each spring. The applied stiffness was calculated directly from the spring stiffness $(\mathrm{N} / \mathrm{mm})$ of each spring (IST, 2015). For example, for a spring applying $1.54 \mathrm{kN}$ of compressive load to the column, the spring stiffness was $15.4 \mathrm{~N} / \mathrm{mm}$. This provided an accurate representation of the trial configuration.

To accurately account for the high thermal loads which cause softening and blast loads which cause high strain and high strain rate effects in structural steels the Johnson Cooke (Johnson, 1983) material model was used. Two samples from each column 
section type were statically tested in accordance with BS EN ISO 6892-1:2016 (BSi, 2016 ) to determine the $0.2 \%$ proof (yield) stress and the ultimate tensile stress. The steel specified for the trial was S355 high yield structural steel (Bsi, 2006a). Table 6 shows results from the static tensile tests. The results show that the SHS average yield strength (528.5MPa) was considerably higher than the CHS (414MPa) and RHS (371MPa). These values were used in combination with the Johnson-Cooke formula to formulate the material model subsequently used in the FEA models. Fig. 25 shows the post elastic material model used for the RHS steel at varying temperatures $20-1100^{\circ} \mathrm{C}$, assuming a constant strain rate of $80 \mathrm{~s}^{-1}$ (van Netten, 1997).

[Fig. 25 and Table 6 near here]

\subsection{Computational Results \& Discussion}

The predictive computational and actual midpoint deflection versus time histories (determined from high speed videos) for the RHS, CHS and SHS from trial 1, rig1 (pinned rig with no thermal or compressive loads) are shown in Fig.26. The peak deflections recorded during the trial are larger than the computational models (RHS = 182.4mm: trial, $79.7 \mathrm{~mm}$ : model). The final deflections between the trial and modelled RHS deflections are closer at $28.3 \mathrm{~mm}$ (trial) and $38.1 \mathrm{~mm}$ (model). The SHS also showed good agreement with the final deflections between the trial $(12.3 \mathrm{~mm})$ and model $(12.8 \mathrm{~mm})$.

[Fig. 26 near here]

Fig. 27 shows the modelled and actual recorded deflections at trial 2 rig 3 (no thermal, low compressive load). A reasonable correlation is observed between the actual response and computational model for the RHS. The actual recorded peak deflection was $161.5 \mathrm{~mm}$, compared to the modelled peak deflection of $131.4 \mathrm{~mm}$. The final 
(settled) deflections were also similar; discounting the camera error at $0.97 \mathrm{sec}$ (sudden decrease) the final deflection of the trial column (RHS) was $43.7 \mathrm{~mm}$, compared with the modelled final deflection of $45 \mathrm{~mm}$. The model results under-predict the actual values for the SHS and CHS.

[Fig. 27 near here]

Fig.28 shows the modelled and actual recorded deflection of the RHS during trial 4 at rig 2 (high thermal, low compressive load). The profile from the analytical model has been smoothed using average smoothing windows of 100 . Similarly to previous predictive models the RHS response shows a reasonable degree of accuracy with the actual results. The peak deflection of the RHS during the trial was $163.7 \mathrm{~mm}$, which is close to the modelled peak deflection of $174.8 \mathrm{~mm}$. Further work to refine numerical models would potentially provide closer correlation between the trial deflections and the model deflections. Improvements to the models would include a more detailed representation of end connections, increased accuracy for applied pressures around the columns and an improved representation of the thermal load along the length of each column.

[Fig. 28 near here]

\subsection{Comparative Studies Discussion}

The trials detailed in this report are the first experimental trials to investigate the effect of combined thermal, axial and long duration blast load on structural steel columns. Other similar studies include the use of an adaptive computational method of analysing steels frames to explosive events and subsequent fire loads as detailed in (Song, 2000), and validated in (Izzuddin, 2000). Three separate material models were adopted into the analysis to take account of variation of Young's modulus with temperature. Findings showed that the initial blast loads reduced the fire resistance of steel structures by $40 \%$. 
(Chen, 2005) used a similar mixed element approach for fire and blast analysis on whole frames. (S. Quiel, Marjanishvili, S., 2013) modelled steel columns subject to fire and explosive loading using a multi-hazard approach with standard blast analysis module codes, the outputs of which were inputted directly into a lumped mass, fire analysis code. The removal of passive fire protection on steel columns subject to an initial blast, followed by a fire is investigated in (S. E. Quiel, Marjanishvili, S. M., 2012). Results showing removal of passive protection reduces time to column stability loss from 30 to 11 minutes. The findings from these papers contribute to the overall understanding of thermal and blast synergistic phenomena on steel structures. However, none investigate the case of a fire/thermal load occurring before a blast therefore direct comparison is limited.

Previous experimental studies undertaken by (Pearson, 1981), investigated the response of small aluminium cylinders to an intense thermal pulse of $25 \mathrm{cal} / \mathrm{cm}^{2}$ as a precursor to a $42 \mathrm{kPa}$ shock wave. Significant differences between the de-coupled and coupled experimental trials were observed; including an increase in compressive strain during the thermal phase leading to buckling, followed by subsequent compressive strain increases until a large tensile strain swing was observed on arrival of the blast load. Final deflected shapes indicated local buckling at connections and larger central deformations with the combined thermal and blast trials in comparison to blast only. There are clear similarities with the increase in compressive strains leading to (potential) buckling, large bending and tensile stresses and observed larger final central deformations. However, the trials only investigated one thermal profile, with no compressive loads and used small aluminium cylinders. 


\section{Conclusions}

This paper details the design and results of three series of experimental trials observing the response of steel column sections subject to combined compressive, thermal and long duration blast load. These are the first experimental trials to be successfully undertaken using combined compression, thermal and long duration blast loading regimes inside an Air Blast Tunnel without the use of highly volatile thermal emitting substances such as aluminium oxide as discussed in Teel, 1981 (Teel, 1981) and Borgatz, 1985 (Borgartz, 1985).

The design and use of a new thermally insulated box and drop down frame enabled heating of structural columns using ceramic heating elements to temperatures of over $500^{\circ} \mathrm{C}$. The thermally insulated box aided a focused and intense heat to be applied to the central $500 \mathrm{~mm}$ length of the columns. Heavy duty springs were used, as a cost effective and practical alternative to hydraulic compression rigs, effectively imparting "in-service" compressive loads to the structural columns without obstructing any blast flow field. Upward trends in peak and final deflections were observed with increasing peak temperatures and applied compression in combination with the blast loads. This correlates well with reduced Young's modulus and yield strength of steel at high temperatures and increased damage potential (buckling) from combined high compressive and bending loads. RHS columns exhibited the largest deflections and exhibited the most notable response from increasing temperatures. CHS columns displayed the smallest response to all load types (thermal, compressive and blast), due to several factors; a (relatively) high buckling capacity, thick gauge steel and a narrow rounded cross section.

Results from these experimental trials quantify the increased damage of steel columns due to combined loading regimes, indicating a sensitivity response envelope at 
particular elevated temperatures $\left(>350^{\circ} \mathrm{C}\right)$ and applied compressive loads in proportion to column buckling capacities. Results from these experimental trials will be used to verify the computational analysis of steel columns to intense thermal and long duration blast loads from explosive events. The design of these experiments have set an important benchmark for practitioners, experimentalists and researchers undertaking combined thermal and blast testing inside an ABT,

\section{Acknowledgement}

The author acknowledges that all results and data reported herein are the property of the UK Ministry of Defence. The assistance of staff at MOD Shoeburyness is gratefully acknowledged with respect to the preparation and undertaking of the trials and for their support during the project. The author would also like to express thanks to the sponsor. With support and contribution from AWE Plc, Aldermaston, UK.

\section{Declaration of Interest}

We wish to confirm that there are no known conflicts of interest associated with this publication and there has been no significant financial support for this work that could have influenced its outcome. We confirm that the manuscript has been read and approved by all named authors and that there are no other persons who satisfied the criteria for authorship but are not listed. We further confirm that the order of authors listed in the manuscript has been approved by all of us. We confirm that we have given due consideration to the protection of intellectual property associated with this work and that there are no impediments to publication, including the timing of publication, with respect to intellectual property. In so doing we confirm that we have followed the regulations of our institutions concerning intellectual property. We understand that the Corresponding Author is the sole contact for the Editorial process (including Editorial Manager and direct communications with the office). He/she is responsible for communicating with the other authors about progress, submissions of revisions and final approval of proofs. We confirm that we have provided a current, correct email address which is accessible by the Corresponding Author and which has been configured to accept email from laurie.clough@port.ac.uk 


\section{References}

Atkinson, G., Cusco, L. (2011). Buncefield: A Violent, Episodic Vapour Cloud Explosion. . Process Safety \& Environmental Protection: Transactions of the Institution of Chemical Engineers, 89(6), pp. 360-370.

Borgartz, B. O. (1985) AWRE Foulness Combined Blast and Thermal Radiation Simulator Installation of the TRS in the Blast Tunnel. Paper presented at the MABS 9 London, England.

Bsi. (1991). Specification for Patented Cold Drawn Steel Wire for Mechanical Springs: British Standards Insitute.

BSi. (2002a). Eurocode 1: Actions on structures Part1-2: General actions - Actions on structures exposed to fire: British Standards Insitute.

BSi. (2002b). Eurocode 1: Actions on structures Part1-1: General actions - Densities, self-weight, imposed loads for buildings: British Standards Insitute.

Bsi. (2005a). Eurocode 1: Actions on Structures: General Actions Wind Actions.

BSi. (2005b). Eurocode 3: Design of Steel Strucutures: General Rules Structural Fire Deisgn: British Standards Institute.

Bsi. (2006a). Cold Formed Welded Structural Hollow Sections of Non-Alloy and Fine Grain Steels Technical Delivery Requirements: British Standards Insitute.

BSi. (2006b). Cold Formed Welded Structural Hollow Sections of Non-Alloy and Fine Grain Steels Tolerances, dimensions and sectional properties: British Standards Insitute.

BSi. (2006c). Eurocode 1: Actions on structures Part1-7: General actions - accidental actions: British Standards Insitute.

BSi. (2016). Metallic materials. Tensile testing. Method of test at room temperature: British Standards Institute.

Burgan, B. (2009). Buncefield Explosion Mechanism Phase 1. H. a. S. Executive.

Ceramicx. (2015). Ceramicx: Ceramic Heating Elements. Retrieved Date Accessed, 2015 from http://www.ceramicx.co.uk/ceramic-elements/.

Chen, H., Liew, J. . (2005). Explosion and Fire Analysis of Steel Frames Using Mixed Element Approach. Journal of Engineering Mechanics, 131(Advances in the Stability of Framed Structures), pp. 606-616.

China explosions: What we know about what happened in Tianjin. (2015). Retrieved Date from http://www.bbc.co.uk/news/world-asia-china-33844084

Clough, L. G. (2017). Synergistic Reponse of Steel Structures to Thermal and Blast Loading (PhD. University of Southampton.

Clough, L. G., Clubley, S.K. (2013) Gauging the Fireball: Simulation and Testing. Paper presented at the Internation Symposium on Interaction of Effects of Munitions with Structures, Potsdam, Germany.

Clough, L. G., Clubley, S.K. (2014) Response of Steel Plates to Thermal and Blast Load from Within the Fireball of an Explosive Event. Paper presented at the Structures under Shock and Impace, New Forest, UK.

Clubley, S. K. (2013). Steel Sections Subject to Long Duration Blast. ICE Proceedings, Journal of Structures and Buildings, 166(6), pp. 273-281.

Clubley, S. K. (2014). Non-linear long duration blast loading of cylindrical shell structures. Engineering Structures, 59, pp. 113-126.

Davison, B., Owens, G.W. (2012). The Steel Designers' Manual (Seventh ed.): Steel Construction Institute. 
Gratias, S. (1987) Combined Thermal and Blast Effects Integration of a Thermal Radiation Simulator Inside the 2.4m Diameter Shock Tube at C.E.G. Paper presented at the MABS 10 Bad Reichenhall, Germany.

Gregory, F. H., Pearson, R. J. . (1982). Analytical and Experimental Studies of the Response of a Cylinder to Nuclear Thermal/Blast Loads. Ballistic Research Labs., Aberdeen Proving Ground, MD, U.S

Griff, N., Proctor. J.F. (1972) A Facility for Simulation of Thermal Radiation Airblast Interaction Effects. Paper presented at the MABS 3 Schwetzingen, Germany.

IST. (2015). IST Spring Calculator Retrieved Date Accessed, 2015 from http://www.springcalculator.com/scp/.

Izzuddin, B. A., Song, L., Elnashai, A.S., Dowling, P.J. . (2000). An Integrated Adaptive Environment for Fire and Explosion Analysis of Steel Frames - Part II: Verification and Application. Journal of Constructional Steel Research, 53(1), pp. 87-111.

Johnson, G. R., Cook, W.H. (1983). A Constitutive Model and Data for Metals Subjected to Large Strains, High Strain Rates and High Temperatures. Proceedings of the 7th International Symposium on Ballistics, $\mathrm{p} 7$.

Loftis, R. L. (2013). Analysis: West Texas fertilizer report details sequence of a catastrophe. Retrieved Date from http://www.dallasnews.com/news/texas/2013/05/16/analysis-west-fertilizerreport-details-sequence-of-a-catastrophe

LUSAS. (2011). User Reference Manual. Surrey, UK.

Pearson, R. J., Wisniewski, H.L., Szabados, P.D. (1981) Synergism in Nuclear Thermal / Blast Loading. Paper presented at the MABS 7 Medicine Hat, Alberta, Canada.

Quiel, S., Marjanishvili, S. (2013). Steel Column Subjected to Fire Following an Explosion. 15th ISIEMS, Potsdam, Germany.

Quiel, S. E., Marjanishvili, S. M. (2012). Fire Resistance of a Damaged Steel Building Frame Designed to Resist Progressive Collapse. Journal Of Performance Of Constructed Facilities, pp. 402 - 409.

Russian meteorite blast explained: Fireball explosion, not meteor shower (2013). Retrieved Date from https:/www.rt.com/news/scientists-explain-chelyabinskbolide-337/.

Shepherd, P. G., Burgess, I. W. (2011). On the Buckling of Axially Restrained Steel Columns in Fire. Engineering Structures, 33(10), pp. 2832 - 2838.

Simon, K., Wenig, P., Serra, J.J. (2008) Reproducibility of Flux and Fluence Levels in Nuclear Thermal Testing. Paper presented at the MABS 20, Oslo, Norway.

Song, L., Izzuddin, B.A., Elnashai, A.S., Dowling, P.J. . (2000). An Integrated Adaptive Environment for Fire and Explosion Analysis of Steel Frames - Part I: Analytical Models. Journal of Constructional Steel Research, 53(1), pp. 63 - 85.

Teel, G. D., and Oertel, F.H. (1981) Testing to Combined Blast and Thermal Effects at the BRL. Paper presented at the MABS 7 Medicine Hat, Alberta, Canada.

van Netten, A. A., Dewey, J.M. (1997). A Study of Blast Wave Loading on Cantilevers. Shock Waves, 7, pp. 175-190.

Zavitsanos, P. D., et al. (1998). Design, Construct and Test of the Hi-Therm Simulator. Souderton, PA, U.S.A 